\title{
Effects of Charging Lithium-Ion Cells with Zero Termination Current on the State of Health (SoH) for Energy Storage Systems
}

\author{
Ali Eren KOK ${ }^{1}$, Ibrahim DEVELI ${ }^{2}$ \\ ${ }^{1}$ Erciyes University \\ Graduate School of Natural and Applied Sciences, Kayseri, Turkey \\ alierenkok44@gmail.com \\ ${ }^{2}$ Erciyes University \\ Faculty of Engineering, Department of Electrical \& Electronics Engineering, Kayseri, Turkey \\ develi@erciyes.edu.tr
}

\begin{abstract}
Lithium-ion (Li-Ion) cells have their own charging method, which is known as Constant Current-Constant Voltage charging method. In this method, all Li-Ion cells are charged by the constant current; after the cells reached the pre-defined charge cell voltage, the constant voltage period begins and lasts until the cells' current drawing is under the current level specified in the datasheet. Nowadays, a battery management system (BMS) controls this charging method for Li-Ion cells. In addition to this, BMS ensures that all Li-Ion cells in the battery pack work in a safe operating area. However, in an energy storage system (ESS), the DC bus bar system is used because there may be different current sources such as solar, wind, etc. As a result of this, there will be a continuous current flow over this DC bus system. Therefore, it will be possible to charge the Li-Ion cells with a value below the charge termination current or with zero charge termination current. In this paper, the effect of applying different charge termination currents to the Li-Ion cells on state of health (SOH) is investigated. We present results about how effect the changes both in charge voltages and charge termination current the life of the cell. As a result of this research, it is aimed to prepare a document that can be used by researchers who want to find information on this subject by presenting the data on the $\mathrm{SoH}$ with visuals and graphics.
\end{abstract}

Keywords: Energy Storage System, Battery, Lithium-Ion battery, SoH, Renewable Energy, Solar Energy

\section{Introduction}

Energy is defined as the ability of an object or system to do work. According to the law of conservation of energy, energy can neither be destroyed nor created from nothing. Energy can change species so there are many different types of energy. The form of energy that has not undergone any change or transformation is known as primary energy. Primary energy sources are oil, coal, natural gas, nuclear, hydraulic, biomass, tidal wave, sun, and wind. The energy obtained as a result of the conversion of primary energy is known as secondary energy. Electricity, gasoline, diesel oil, diesel, coke, secondary coal, petroleum coke, air gas, and liquefied petroleum gas (LPG) are known as secondary energy sources [1,2].

Energy sources are generally classified according to their use and recyclability. There are two types of classification according to the use of the energy source. These are renewable and non-renewable. On the other hand, in the case of recyclability, there are also two types of classification. As explained above, these are primary energy sources and secondary energy sources.

Globally, there are various application areas for the usage of the energy storage system since it provides flexibility to the grid network [3]. Today, it is known that almost every individual has at least one of the portable electronic devices (computers, mobile phones, cameras, cameras, MP3 players, CD players, DVD players, radios, televisions) for fast and efficient communication [4]. In addition to this, due to the advanced technology, the need for the wireless system increases day by day. Electronic products' vital need to maintain their functions for a long time is to have an energy source with high 
energy density. Moreover, it should also provide some essential features such as being safe, long-lasting, easy to maintain, rechargeable in a short time, and does not harm the environment. Rechargeable/secondary (lithium-ion (Li-Ion)) batteries are widely used today in portable electronic and electrical equipment due to their superior features [5].

The energy storage system can be used to store energy when the price of the energy is low. Thanks to this way, the stored energy can be used when the electricity prices are high. In addition to this, the solar system's energy can be stored in the ESS, and it can be sold to the grid network. As a result of this, it can be possible to gain economic gain by the users [6]. There are three main reasons for storing electrical energy [7]:

- Power Quality: Storing the energy during short periods in order to increase the quality of the energy

- Bridging Power: Storing the energy to ensure the continuity of energy in the case of the possible interrupt that may occur in the electricity network.

- Energy Management: It is the storage of energy when it is cheap and uses the stored energy in times of need.

Secondary (rechargeable) batteries are used in fixed storage systems because of their advantages, such as fast response times, high energy capacities, and high storage efficiency [8,9]. The batteries inside the energy storage system (ESS) may differ according to the chemistries used in the anode and cathode. There is various chemistry technology used in the ESS. These different chemistries are: Lithium-Ion (Li-Ion), Sodium Sulfur (NaS), Zinc Bromine (ZnBr), Vanadium Redox, Metal Air, Nickel Cadmium (NiCd), Polysulfide Bromide (PSB), Lead Acid. These technologies should be researched concerning their prices, performance, and stability. Among these different chemistries, lead-acid batteries are the oldest battery type and most mature technology used in power system applications.

Batteries such as Lithium-Ion (Li-Ion), Sodium Sulfur, Nickel Cadmium (NiCd) are mainly used for the system that needs more power density [10]. Among these battery technologies, it is estimated that Li-Ion will have great potential for development and stability in the near future. In addition to their small size and weight, Li-ion batteries offer nearly $100 \%$ storage capacity and also high energy density. With these great features, it emerges as an ideal solution for portable / mobile energy storage systems. Even though metal-air batteries seem to be an ideal system due to their high energy density and low cost, this kind of battery's recharging process is more complicated [11].

\section{Lithium-Ion Batteries}

Since Sony's commercial production in 1991, the use of Li-Ion batteries has quickly become widespread in different areas. In addition to the general use of Li-Ion batteries in electronic devices such as laptops, MP3 players, and mobile phones, using this technology in electric vehicles and alternative energy sources is expected to increase rapidly shortly. In this aspect, tens of millions of Li-Ion battery units have been produced each year [12, 20]. Li-Ion batteries have a much better energy storage efficiency that closes to $100 \%$ and also has the highest energy density among other battery technologies. Li-Ion batteries have a light structure, a relatively high voltage level of about $4 \mathrm{~V}$ per cell, and a higher energy level of 100-150 Wh / $\mathrm{kg}$ to other cell chemistries. However, this technology's disadvantages are the high initial investment cost for band procurement and the complex charging management system due to sensitive operating limits [12, 20]. The cost of Li-Ion batteries varies between 360-1000 Euro / kWh [15]. Also, the electrolyte structures in Li-Ion batteries are thermodynamically irregular.

Conditions like overcharging can lead to relatively permanent harm to the structure of Li-Ion batteries [20]. Moreover, the low cycle life, the varying performance depending on the operating temperature, and the chemicals used in its internal structure are relatively difficult to find are the main obstacles to the more frequent use of Li-Ion batteries today. To improve the sensitive chemical structure of Li-Ion batteries and also to provide more frequent use in structures where durability is at the forefront, such as electric vehicle applications, research studies are continuing intensely today. These studies have focused 
on developing alternative materials for use in the electrode structure of Li-Ion batteries and cost reduction [12, 20]. Lithiumsilicon (LiSi), lithium-tin ( $\mathrm{Li}-\mathrm{Sn})$, etc. materials are frequently investigated for use in the construction of lithium-based batteries. Besides, the replacement of graphite and lithium cobalt oxide materials in the structure of Li-Ion batteries with higher capacity and lower-cost alternatives is an issue that is frequently emphasized [20]. With the research and development studies carried out, it is predicted that Li-Ion battery systems will be one of the pioneer battery types in the future.

Li-Ion battery technology is known as secondary batteries. They are electrochemical cells that can be recharged and used after discharge. In Table 1, the advantages and disadvantages of Li-Ion batteries compared with other secondary batteries (silver-zinc, nickel-zinc, nickel-hydrogen) are listed [21].

Table 1: Advantages and Disadvantages of Rechargeable Li-Ion Batteries [21].

\begin{tabular}{|c|c|}
\hline Advantages & Disadvantages \\
\hline Long life & Vulnerability to high operating temperature \\
\hline Wide operating temperature range & Protection Circuit need \\
\hline Long shelf life & Capacity loss due to overcharge and thermal \\
& harm Cost \\
\hline Quick Charging Capability & \\
\hline Quick Discharging Capability & \\
\hline High Energy Efficiency & \\
\hline No battery memory effect & \\
\hline
\end{tabular}

In rechargeable Li-Ion batteries, cells consist of three main components primarily responsible for supplying and storing energy as in other battery systems. These can be contented as anode, cathode, and electrolyte [22]. The anode material serves as the negative electrode and the cathode as the positive electrode. Positive electrodes are generally composed of metal oxides (LiMOx) with a tunnel or layered structures. They have layered structures in negative electrode materials. Thanks to these structures, Li-Ions can exchange between positive and negative electrodes during charging and discharging of the cell/battery $[22,23]$. This is defined as the displacement reaction. In this reaction, the active materials are anode and cathode and serve as hosts for lithium, while lithium is displaced from one electrode to another as a guest [23, 24].

Lithium metal is used in rechargeable batteries such as mobile phone batteries, camera batteries, and aviation vehicles as an alloy. In its simplest form, a battery consists of two electrodes, one positive and one negative. It contains an ironically conductive, electrically insulating electrolyte that separates these two electrodes from each other. The advantages of lithiumbased energy storage systems over other storage methods can be listed as follows;

- Very long storage life,

- They can provide longer constant voltage,

- Providing opportunities at low and high temperatures,

- Having high energy density and high nominal voltage,

- High level of elasticity,

- Has high charging efficiency,

- Long cycle life [25, 26]

\section{Lithium-Ion Battery SoC and SoH Determination}

\subsection{Determining Battery Models and State of Charge (SoC)}

Thanks to the advanced battery technology, the interest in batteries increases day by day. Until the invention of Li-Ion technology, nickel-cadmium, and lead-acid batteries were the primary power source for portable electronic devices for years 
[27]. However, with Li-Ion technology, Li-Ion batteries are preferred in the portable devices industry since Li-Ion has some advantages, such as having a stable operating voltage, high energy density, high cycle life, and low weight [28].

Since the use of new technology Li-Ion batteries is not very economical, they are not preferred as widely as lead-acid batteries. Even though the battery is a simple chemical energy source, there is no direct access to the amount of chemical energy stored in the battery. As a result of this, it is very complicated and difficult to directly measure the state of charge (SoC) of the battery [29]. Different studies are stating and proving that the battery management system (BMS) increases power consumption efficiency and battery life [30,31]. For real-time battery protection, BMS is used to regulate battery charge and discharge processes and also monitor battery status [32, 33].

The precision SoC estimation is vital in battery usage, but it is also tricky. Estimating a battery's remaining capacity protects the battery, prevents over-discharge, and increases battery life [34]. It also allows the creation of an intelligent control strategy for energy saving in applications [35]. However, SoC's accurate estimation is very complex and challenging to implement since battery models are limited and parametric differences exist between the available battery models [36]. In practice, there are different methods of estimating SoC [37].

\subsection{Determining Battery State of Health (SoH)}

State of Health $(\mathrm{SoH})$ is the term that is used to describe the battery's ability to energize the load. In other words, it provides a clear idea of whether the battery needs to be replaced or how much the battery can be used without changing the battery. The capacity of the battery decreases gradually as the battery is used (ages). For this reason, although the charge status shows $100 \%$, the actual capacity stored in the battery may not be the same as the time when it was new. For a battery to be charged/discharged safely and be used healthily without decreasing its life, the battery must be operated in a specific SoC range. This operating range may vary depending on the use of the battery and the charge/discharge frequency.

In practice, this operating range differs from $20 \%$ to $90 \%$. The reason for doing this is to prevent the overcharge/discharge of the battery since overcharging or discharging the battery may change the internal resistance of the cells. As a result of this, the usable capacity of the battery may decrease. In order to prevent this kind of problems, batteries must be worked in a safe operating area.

SoH measurement can be done by comparing the battery pack's current capacity with a new battery pack's capacity. There are different methods to measure the SoH of the battery cells, like impedance tracking, self-discharge rate, etc. [38]. There are four definitions of SoH based on the characteristics of the battery [39];

1- SoH formula related to the remaining power in the battery can be given as:

The formula used to determine the $\mathrm{SOH}$ battery in terms of the remaining power of the battery.

$$
\text { SoH }=\frac{C C A_{\text {ocmp }}-C C A_{\text {min }}}{C C A_{\text {new }}-C C A_{\text {min }}} x 100 \%
$$

$\left(\mathrm{CCA}_{\text {ocmp }}=\right.$ The real-time power of the battery, $\mathrm{CCA}_{\text {new }}=$ Estimated starting power released by the battery when SOC is $100 \%, \mathrm{CCA}_{\min }=$ the minimum required power)

2- The $\mathrm{SoH}$ expression given in comparison to the initial power is given as:

The formula is used to determine $\mathrm{SOH}$ from the initial power.

SoH $=\frac{Q_{\text {aged }}}{Q_{\text {new }}} x 100 \%$

$\left(Q_{\text {aged }}=\right.$ remaining capacity of the battery when aged, $Q_{\text {new }}=$ the capacity of a new battery)

3- The formula used to determine $\mathrm{SOH}$ from the impedance of the battery is given as:

The formula is used to determine $\mathrm{SOH}$ from impedance measurement data.

$$
\text { SoH }=\frac{R_{i}}{R_{0}} x 100 \%
$$

$\left(\mathrm{R}_{\mathrm{i}}=\right.$ The final impedance of the battery, which changes with the charge and discharge cycles, $\mathrm{R}_{0}=$ Initial impedance of the battery)

4- The SoH expression given in comparison to the capacity power of the battery is given as:

The formula used to determine $\mathrm{SOH}$ in terms of battery capacity power.

$$
\text { SoH }=\frac{C_{i}}{C_{0}} x 100 \%
$$


$\left(\mathrm{C}_{\mathrm{i}}=\mathrm{i}\right.$ th capacity value of the battery degenerated by cycles, $\mathrm{C}_{0}=$ the initial capacity of the battery)

\section{Results}

The methods for determining the health status of batteries are shown in the equations given above. In this paper, Equation-4, a measurement method with battery capacity power, was used to determine the cell's health status. According to this equation, the initial capacities of the batteries are calculated. Then, the final capacities of the batteries that were charged/discharged for a long time using specific charging methods were measured and compared. In this way, the state of health $(\mathrm{SoH})$ of the battery has been determined.

Batteries are considered fully charged if the current level flowing into the battery is under the charge termination current, specified in the battery's datasheet. However, in any project, there is a DC bus connected to the input of the battery. Thus, there is always a charge current floating into the battery since there is also a charge voltage between the battery terminals.

In this paper, cells with different charging voltages and charge termination currents are tested. Thus, different results were obtained at different charge termination currents and evaluated comparatively. In order to determine the SoH of the battery, equation -4 , which is well explained above, is used. Moreover, the initial and final capacities of the cells were compared. For the measurements' consistency, two separate cells were examined by charging/discharging in different profiles.

The results of the tests are given in Table- 2 below. Tests were carried out using 8 NMC cells. Four different charge/discharge processes were applied to the cells. In order to compare the data, the standard charging method and charging processes with zero charge termination current at different voltage levels were applied to the cells $(4,2 \mathrm{~V} 50 \mathrm{~mA} / 4,2 \mathrm{~V} 0$ $\mathrm{mA} / 4,1 \mathrm{~V} 0 \mathrm{~mA} / 4,0 \mathrm{~V} 0 \mathrm{~mA}$ ). In order to obtain correct results, the same process was applied to both cells. A 500 cycle life is given in the cell's datasheet. A total of 144 cycle tests were conducted. This corresponds to approximately $30 \%$ of the life span of the cell.

Table-2 Data obtained as a result of the tests performed

\begin{tabular}{|l|l|l|l|l|l|l|l|l|l|}
\hline $\begin{array}{c}\text { Battery } \\
\text { Name }\end{array}$ & $\begin{array}{c}\text { Test } \\
\text { No }\end{array}$ & $\begin{array}{c}\text { Charge } \\
\text { Voltage } \\
(\mathbf{D C})\end{array}$ & $\begin{array}{c}\text { Charge } \\
\text { Termina- } \\
\text { tion } \\
\text { Current }\end{array}$ & $\begin{array}{c}\text { The Initial } \\
\text { Capacity } \\
(\mathbf{m A h})\end{array}$ & $\begin{array}{c}\text { Last } \\
\text { Capacity } \\
(\mathbf{m A h})\end{array}$ & $\begin{array}{c}\text { Loss } \\
\text { of Capacity } \\
(\%)\end{array}$ & $\begin{array}{c}\text { SoH } \\
\mathbf{\%})\end{array}$ & $\begin{array}{c}\text { Usable } \\
\text { Capacity } \\
(\%)\end{array}$ & $\begin{array}{c}\text { Cycle } \\
\text { No }\end{array}$ \\
\hline NMC-1 & PS1 & $4,2 \mathrm{~V}$ & $50 \mathrm{~mA}$ & 2711 & 2654 & 2,10 & 97,90 & 99,7 & 144 \\
\hline NMC-2 & $\mathrm{PS} 2$ & $4,2 \mathrm{~V}$ & $50 \mathrm{~mA}$ & 2744 & 2696 & 1,75 & 98,25 & 99,96 & 144 \\
\hline NMC-3 & $\mathrm{P} 1 \mathrm{~S} 1$ & $4,2 \mathrm{~V}$ & $0 \mathrm{~mA}$ & 2690 & 2581 & 4,05 & 95,95 & 100,52 & 144 \\
\hline NMC-4 & $\mathrm{P} 1 \mathrm{~S} 2$ & $4,2 \mathrm{~V}$ & $0 \mathrm{~mA}$ & 2752 & 2625 & 4,61 & 95,39 & 100,7 & 144 \\
\hline NMC-5 & $\mathrm{P} 2 \mathrm{~S} 1$ & $4,1 \mathrm{~V}$ & $0 \mathrm{~mA}$ & 2695 & 2626 & 2,56 & 97,44 & 91,28 & 144 \\
\hline NMC-6 & $\mathrm{P} 2 \mathrm{~S} 2$ & $4,1 \mathrm{~V}$ & $0 \mathrm{~mA}$ & 2735 & 2673 & 2,27 & 97,73 & 91,92 & 144 \\
\hline NMC-7 & $\mathrm{P} 3 \mathrm{~S} 1$ & $4,0 \mathrm{~V}$ & $0 \mathrm{~mA}$ & 2700 & 2649 & 1,89 & 98,11 & 76,81 & 144 \\
\hline NMC-8 & $\mathrm{P} 3 \mathrm{~S} 2$ & $4,0 \mathrm{~V}$ & $0 \mathrm{~mA}$ & 2741 & 2699 & 1,53 & 98,47 & 77,23 & 144 \\
\hline
\end{tabular}


When the data obtained are examined, it has been determined that the SoH value remains higher in cells with $4.0 \mathrm{~V}$ charge voltage and $0 \mathrm{~mA}$ charge termination current compared to other cells. However, in this method, the usable capacity of the cells is around \%76. It is clearly seen that the $\mathrm{SoH}$ value is meager in the cells where the standard charging voltage of $4.2 \mathrm{~V}$ and $0 \mathrm{~mA}$ charge termination current is applied. This method is not considered a correct method to charge the battery however, cells that are charged with a $4.1 \mathrm{~V}$ charging voltage and $0 \mathrm{~mA}$ charge termination current have $91 \%$ percent usable capacity. When compared this method with the standard charging method, it can be seen that the SoH difference is around $\% 0.5$ percent. It can be considered that this charging method will be suitable for the energy storage system.

\section{Conclusion}

This paper has presented the results about the effect of applying different charge termination currents to the Li-Ion cells on state of health (SOH) of cells. Especially in energy storage systems, which are expected to become widespread and become a necessity in our country in the coming years, batteries will be charged and exposed to a continuous current during the time they are used with solar energy. If the cells are charged with the wrong charging method, this will shorten their life considerably. As a result of the tests performed to find the correct charging method, it was seen that the health of the cells was negatively affected when standard charging voltage and zero charge termination current were used. The charging process to be done in this way will shorten the life of the cells. However, when the charge voltage is reduced slightly (4.1V) and charged with zero charge termination current, it has been observed that the health status of the cells is very close to the standard charge voltage and the standard charge termination current. In addition, this usable capacity loss is around $9 \%$. This is an acceptable value. It is evaluated that the charging method made in this way will be correct. If you reduce the charging voltage too much, the available capacity will be greatly reduced. This means that you use more cells to achieve the desired capacity. This process will increase the cost enormously. In addition to this, the correct charging method for the SoH may decrease the installation costs, optimize the system's life.

\section{Acknowledgments}

This work was supported by The Scientific Research Projects Coordinating office of Erciyes University (Project No: FYL-2019-8874).

\section{References}

[1] Koc, E., Senel, M.C. "Energy Situation in Turkey and the World- General evaluation (in Turkish)," Engineer and Mechanical Magazine, 2013, vol. 54, pp. 32-44.

[2] Senel, M. C. "Design Principles of Power Transmission Mechanisms in Wind Turbines - Dynamic Behavior (in Turkish), Master Thesis, Ondokuz Mayis University, Institute of Science,” Samsun, 2012.

[3] Dogan, H., Yilankiran, N. "Turkey's Energy Efficiency Potential and Projections (in Turkish)," Gazi University Journal of Science, 2012, vol. 1, pp. 375-384.

[4] Yoshio, M., Brodd, R.J. and Kozawa, A., Lithium-Ion Batteries: Science and Technologies, Springer Science and Business Media, Newyork, USA, 2009, pp. 1-7.

[5] Hackney, S.A. ,Kumar, R.V. "High Energy Density Lithium Batteries," Wiley-VCH Verlag GmbH, Weinheim, 2010, pp. 70-73.

[6] Bayram, Islam Safak, Tajer Ali, "Plug-in Electric Vehicle Grid Integration,” MA, USA, 2017, pp. 276.

[7] Mazman, M., Kaypmaz, C., Uzun, D., Bicer, E., Yildiz, A., Tiris, M. "Electrical Energy Storage Technologies for Renewable Energy (in Turkish)," Solar Future 2010 Proceedings Book, İstanbul, 2010, pp. 113-118.

[8] Hajimolana ,S.A., Soroush ,M. "Dynamics and Control of a Tubular Solid-Oxide Fuel Cell," Ind. Eng. Chem. Canada Wiley, 2009, vol. 48, pp. 6112-6125.

[9] Chakrabarti, M.H., Hajimolana, S.A., Mjalli,F.S., Mustafa, I., Saleem, M. "Redox Flow Battery for Energy Storage", Arab J Sci Eng, 2013, vol. 38, pp. 723-739. 
[10] E.Ozdemir, A.Caliker, I.M.Koc, "Hybrid Energy Storage Technologies for Electric Power Systems Fed from a Renewable Energy Source (in Turkish)," ICCI Energy and Environment Fair and Conference Proceedings, 2014, pp. 68-72.

[11] A.Caliker, E.Ozdemir, "Modern Energy Storage Systems and Their Usage Areas (in Turkish)," 5th Energy Efficiency and Quality Symposium, 2013, pp. 175-179,

[12] Garimella, N., Nair, N.K.C. "Battery energy storage systems: Assessment for small-scale renewable energy integration", Energy and Buildings, 2010, vol. 42, pp. 2124-2130.

[13] Baker, J. "New technology and possible advances in energy storage", Energy Policy, 2008.

[14] Kurzweil, P. "Gaston Planté and his invention of the lead-acid battery-The genesis of the first practical rechargeable battery”, J. Power Sources, 2010, vol. 195, pp. 4424- 4434.

[15] Divya, K. C., Østergaard, J. "Battery energy storage technology for power systems-An overview", Electric Power Systems Research, 2009, vol. 79, pp. 511-520.

[16] Dustmann, C. H., “Advances in ZEBRA batteries", J. Power Sources, 127, 2004, 85-92.

[17] Burke A. "Ultracapacitor: why, how and where is the technology", J. Power Sources, 2000, vol. 91, pp. 37-50.

[18] Carlen M., Kötz, R. "Principles and applications of electrochemical capacitors", Electrochimica Acta, 2000, vol. 45, pp. 2483-2498.

[19] Efthimiou, V., Hadjipaschalis, I., Poullikkas, A. “Overview of current and future energy storage technologies for electric power applications", Renewable and Sustainable Energy Reviews, 2009, vol. 13, pp. 1513-1522.

[20] Scrosati, B., Garche, J. "Lithium batteries: Status, prospects and future", J. Power Sources, 2010.

[21] Linden, D., Reddy, T.B. "Handbook of Batteries, Third Eddition, McGraw-Hill”, 2002, vol. 1, pp. 22 - 35.

[22] Nazri, G.A. and Pistoia, G., Lithium Batteries: Science and Technology, Springer Science and Business Media, Newyork, 2009, vol. 1, pp. 8-11.

[23] Ozawa, K., Lithium-Ion Rechargeable Batteries, Wiley-VCH Verlag GmbH, Weinheim, 2009, vol. 2, pp. 5-8.

[24] Akbulut, H., Alp, A., Guler M.O., Uysal, M., Karslioglu, R. Rod and wire like morphologies of thin oxide developed with plasma oxidation after electro deposition, Materials Letters, 2009, vol. 63, pp. 422-424.

[25] The World of Batteries (Functions, Systems Disposal) GRS Batterien, Germany, 2007, vol. 1, pp. 9.

[26] T. Çarkit, M. Alci "Investigation of the Place of Battery Technologies in Energy Storage Systems(in Turkish)," Renewable Energy Resources Symposium (YEKSEM), Antalya,2017, vol. 9, pp.79-80.

[27] C. Sinkaram, V. S. Asirvadam and N. B. Mohd Nor, "Capacity study of lithium ion battery for hybrid electrical vehicle (HEV) a simulation approach," 2013 IEEE International Conference on Signal and Image Processing Applications, Melaka, Malaysia, 2013, pp. 112-116.

[28] Erdinc, O., Uzunoglu, M., Vural, B. "A dynamic lithium-ion battery model considering the effects of temperature and capacity fading," Clean Electrical Power, 2009, pp. 383-386.

[29] Doring, H., Garche, J., Jossen, A., Spath, V. "The detection of the state of health of lead-acid batteries," in Telecommunications Energy Conference, INTELEC 97, 1997, pp.681-686.

[30] Dubarry, M., Hwu R., Liaw, B., Svoboda V. "Capacity loss in rechargeable lithium cells during cycle life testing: The importance of determining state-of-charge," Journal of Power Sources, 2007, vol. 174, pp. 1121-1125.

[31] F. Conte "Battery and battery management for hybrid electric vehicles: a review," Elektrotechnik und Informationstechnik, 2006, vol. 123, pp. 4224-431.

[32] Chiasson ,J., Vairamohan B."Estimating the state of charge of a battery" IEEE Trans. Control Syst. Technol., 2006, vol. 13, pp. 456-470.

[33] G. L. Plett "Extended Kalman filtering for battery management systems of LiPB-based HEV battery packs: Part 3. State and parameter estimation" J. Power Sources, 2004, vol. 134, pp. 107-115.

[34] Guo, H.Q., He,H.W. ,Xiong,R. "Online estimation of model parameters and state-of-charge of LiFePO4 batteries in electric vehicles,” Applied Energy, 2012, vol 89, pp. 413-420. 
[35] Cai, Z.H., Luo, J., Liu, G. F. "Research state of charge estimation tactics of nickel-hydrogen battery," in Proceedings of the International Symposium on Intelligence Information Processing and Trusted Computing (IPTC '10), 2010, pp. 184-187.

[36] Elgammal,A.A.A., Sharaf, A.M."Self-regulating particle swarm optimised controller for (photovoltaic-fuel cell) battery charging of hybrid electric vehicles," IET Electrical Systems in Transportation, 2012, vol. 2, pp. 77-89.

[37] Hess H., Prajapati, 38.V., William, E.J. "A literature review of state of-charge estimation techniques applicable to lithium poly-carbon monoflouride (LI/CFx) battery," in Proceedings of the India International Conference on Power Electronics (IICPE '10), 2011.

[38] E. I. Tezde, I. Okumus, "Battery Models and State of Charge (SoC) Determination (in Turkish)," EMO Scientific Journal, 2018, vol.8, pp. 21-25.

[39] D. Le and X. D. Tang, "Lithium-ion Battery State of Health Estimation Using Ah-V Characterization," in Proceedings of the Annual Conference of the Prognostics and Health Management Society, 2011, vol. 73, pp. 367-373. 